\title{
Impact of anxiety on stuttering: Neurobehavioral aspects
}

\author{
Ranbir Singh ${ }^{1, *}$, Shamsher Singh ${ }^{2}$, Amit Sharma ${ }^{3}$, Richa Arya ${ }^{4}$ \\ ${ }^{\mathbf{1}}$ Research Scholar, ${ }^{\mathbf{2}, \mathbf{3}}$ Associate Professor, ${ }^{\mathbf{1 , 3}}$ Dept. of Pharmacy Practice, ${ }^{\mathbf{2}}$ Dept. of Pharmacology, ISF College of Pharmacy, G.T. \\ Road Moga, Punjab, ${ }^{4}$ Speech Practioner, Dept. of Speech and Audiology, Baba Farid University of Health Sciences, Faridkot, \\ Punjab, India
}

*Corresponding Author:

Email: shamshersinghbajwa@gmail.com

\begin{abstract}
Purpose: To investigate the impact of anxiety related stuttering and severity of stuttering related to neurobehavioral changes including demographics of the people who stutter.

Materials and Method: A case-control observational study was conducted and data were collected from the subjects by data collection form for stuttering and an anxiety scale by taking an interview regarding his/her stutter and was analyzed in SPSS Ver. 20.

Result: A total of 180 subjects were included in the study and were divided into three groups that is stuttering with anxiety, stuttering alone and control group. The results of the present study revealed a significant difference between people who stuttered and people who did not stutter on measures of anxiety. Anxiety had a direct impact on stuttering subjects when the stuttering parameters were taken into consideration. The severity of stuttering was associated with the degree of anxiety. The results of the present study also revealed that there is a significant relationship between anxiety and the neurobehavioral changes in stuttering subjects.

Conclusion: A wide variability of scores on the Hamilton scale of Anxiety and the data collection form for stuttering suggests that the levels of anxiety were individualized and there was a sub-group of stuttering subjects who had little or no impact of anxiety on their stutter. The hypotheses were supported by statistical analysis.
\end{abstract}

Keywords: Stuttering, anxiety, Hamilton Anxiety Rating Scale, Neurobehavioral changes.

\section{Introduction}

Stuttering is characterized by a disruption in the flow of normal speech production..$^{1-3}$ Primary behaviors of stuttering include repetitions of syllables or words, prolongations of sounds, and blocks, which disallow the occurrence of a sound for an unusually long period of time. ${ }^{4}$ It has been evident that the total incidence of stuttering is around $1 \%$ worldwide which also include both pre-school children and other school students. Some of the studies showed that the rate of incidence is greater in the male population as compared to the female population. Around $80 \%$ of individuals who stutter will recover from their disfluency, but this is not sure for all to become normal. It has been noticed that most children start to stutter before their adolescence stage that includes the age of 2 to 5 years. It has been reported that nearly $5 \%$ of all children have to go through some stage of stuttering which may last for a period of few weeks to years. The number directs that about $75 \%$ of all children overcome their stuttering naturally. It has been reported that males stutter 3 to 4 times more than females do which makes the male population more to suffer.

The relationship between stuttering and anxiety has been strongly discussed over the decades and it is assumed that anxiety plays a vital role in the pathogenesis of this fluency disorder ${ }^{5-6}$ However, few pieces of evidence are available associated to the stuttering but in some reports, it is evidenced that anxiety affects the rate of stuttering. So, therefore there is a need to explore the hidden targets in this area. Individuals who stutter often have a negative attitude during speaking situations and thus this potentiates the anxiety during such situations. ${ }^{7-8}$ Adults who stutter in particular often receive their negative attitudes from years of dealing with stuttering in a variety of situations and frequently believe that listeners view them as anxious. Anxiety is complex in its construct and can be characterized by an apprehension towards certain future situations. $^{9}$ Behavioral manifestations often include avoidance of situations in which anxiety often occurs. ${ }^{10,11}$ Some studies have concluded that individuals who stutter were no more anxious or depressed than individuals who did not stutter. ${ }^{12}$ The Inventory of Interpersonal Situations (IIS) for the frequency distribution of scores for assessing social anxiety advises that there could be a sub-group of individuals who stutter with high grades of social anxiety compared to those of psychiatric others. ${ }^{13}$ The existence of a sub-group is exceeding socially. The degree of discomfort in social situations, and also the frequency with which these situations arise, are affected among the anxious individuals who stutter during social skill training. ${ }^{14,15}$

Craig and co-workers suggested a strong relation between degrees of association of anxiety and stuttering. For example, many of the physiological responses to anxiety have been found in individuals who stutter are maybe due to increased Cortisol levels. 
Individuals who stutter have also been shown to have increased social and cognitive anxiety levels when compared with individuals who do not stutter. Adults who stutter were found to engage less frequently in social interactions and showed increased levels of cognitive stress during demanding interactions. ${ }^{16}$ Finally, the use of multidimensional approaches when studying anxiety and stuttering, the relation between the two entities can be better understood and more clearly defined. ${ }^{17}$ Studies show that negative emotion related to stuttering expands to social anxiety in some of the individuals. ${ }^{18}$ Since it is observed from earlier literature that there is a remarkable effect of social anxiety on one's emotional and social performance, there is a need to analyze the existence of social anxiety in people who stutter. ${ }^{19-21}$ Thus the purpose of the present study was aimed to analyze the impact of anxiety related stuttering vs. normal individuals, the severity of stuttering related to neurobehavioural changes and to find out the demographics of people who stutter.

\section{Materials and Method Participants}

The subjects participated in the present study were recruited on the basis of study criteria i.e. inclusion and exclusion criteria. Numbers of subjects enrolled in this investigation were 80 adults who stuttered. The diagnosis of the type of stuttering (alone or with anxiety) was made by 2 speech-language pathologists on the basis of Hamilton Anxiety Rating Scale taken into consideration. The subjects who did not stutter were taken as control group consisted of 80 subjects as well. On the basis of study criteria, the subjects in the age range of 18-40 years were taken in the present study as groups i.e. stuttering with anxiety, stuttering alone and control. As for exclusion criteria, the patients who were not willing to participate in the study, patients below the age of 18 and above the age of 40 were excluded from the study. Pregnant and lactating women were not taken in the study. Total number of male subjects was 130 and females were 30 so it is important to indicate that $81.2 \%$ participants from all the three groups in the present study were males and just $18.8 \%$ were females, therefore an unequal distribution of gender was very high, making it challenging to create assumptions in concern to levels of anxious mood on the basis of gender.

\section{Procedure}

The work was carried out after obtaining approval and clearance from the Institutional Ethics Committee and the study was conducted at Speech and Audiology Department/O.P.D; Guru Gobind Singh Medical College \& Hospital, Faridkot, Punjab, India. The study was designed as a case-control observational study. The proposed study was divided into four phases: a) Review of literature and collection of data, b) Compilation of data, c) Analysis and interpretation of compiled data, d)
Compilation of results. Based on the inclusion and exclusion criteria the subjects were asked to sign an informed consent form. The data was collected from the subjects through a data collection form for stuttering carrying a set of questions approved by two well experienced speech-language pathologists and by administrating Hamilton Anxiety Rating Scale (Appendix A) which carries a set of anxiety parameters. $^{22}$ The anxiety levels of the subjects were noted down on the basis of ratings given by the scale ranging from 0-4 i.e. not present to very severe. Data was basically collected by taking an interview regarding his or her stutter which was held for a period of 10-15 min individually. As for control group, the same procedure of data collection was followed. Various categories of subjects such as college students, hospital staff, colleagues and general population participated as a control.

\section{Statistical analysis}

Statistical analyses of the data collected were done via IBM SPSS Statistics version 20. The inter-variable and statistical difference between each group was done by one-way ANOVA followed by Tukey's post-hoc test (.05 was used as a level of significance i.e. 95\% was taken as confidence interval and the mean difference was significant at the 0.05 level). The number of dependent variables that were investigated was 7 .

Anxious mood, Repetition of words, Prolongation of words, Blockage of words, Facial movements, Hand movements, other body movements.

\section{Result}

\section{Demographics of the subjects (frequency distribution)}

Age category distribution of subjects

The mean (mean \pm S.D) of age category distribution of the subjects was $26.23 \pm 6.028$ and the median was 25.00. Test of proportion has shown that most of the subjects, i.e. $55(34.4 \%)$ were significantly higher in the 18-22 age category of the subjects than other age categories of the subjects i.e. 23-27(28.7\%), 28$32(19.4 \%), 33-40(17.5 \%)$.

\section{Gender distribution of subjects}

The mean (mean \pm S.D)* of the gender distribution of the subjects was $1.19 \pm 0.392$ and the median was 1 . Test of proportion has shown that most of the subjects, i.e. $130(81.3 \%)$ were significantly higher in the male distribution of subjects than the female distribution of subjects.

\section{Family history distribution of subjects}

The mean (mean \pm S.D)* of family history distribution of the subjects was $1.79 \pm 0.406$ and the median was 2. Test of proportion has shown that most of the subjects, i.e. $127(79.4 \%)$ were significantly 
higher in number with no family history than the other subjects with family history.

\section{Repetition of words distribution of subjects}

The mean (mean \pm S.D)* of repetition of words distribution of the subjects was $3.98 \pm 1.675$ and the median was 5 . Test of proportion has shown that most of the subjects, i.e. $108(67.5 \%)$ were significantly having no repetition of words than the other subjects who repeated the words as follows: 2-3 times (19.4\%), 4-5 times (8.8\%), 6-7 times (3.1\%), more than seven times $(1.3 \%)$.

\section{Prolongation of words distribution of subjects}

The mean $($ mean \pm S.D)* of prolongation of words distribution of the subjects was $3.74 \pm 1.714$ and the median was 5 . Test of proportion has shown that most of the subjects, i.e. $101(63.1 \%)$ were significantly higher in number with no prolongation of words than the other subjects with prolongation of words as follows 2-3 seconds (20\%), 4-5 seconds (13.1\%), 6-7 seconds $(3.1 \%)$, more than seven seconds $(0.6 \%)$.

\section{Blockage of words distribution of subjects}

The mean $($ mean \pm S.D $) *$ of blockage of words distribution of the subjects was $1.64 \pm .480$ and the median was 2 . Test of proportion has shown that most of the subjects, i.e. $103(64.4 \%)$ were significantly higher in number with no blockage of words than the other subjects with blockage of words i.e. 57(35.6\%).

\section{Facial movements distribution of subjects}

The mean (mean \pm S.D)* of facial movements distribution of the subjects was $1.63 \pm .484$ and the median was 2 . Test of proportion has shown that most of the subjects, i.e. $101(63.1 \%)$ were significantly higher in number with no facial movements than the subjects with facial movements i.e. 59 (36.9\%).

\section{Hand movements distribution of subjects}

The mean (mean \pm S.D)* of hand movements distribution of the subjects was $1.67 \pm .472$ and the median was 2 . Test of proportion has shown that most of the subjects, i.e. 107 (66.9\%) were significantly higher in number with no hand movements than the other subjects who showed hand movements i.e. 53 $(33.1 \%)$.

\section{Other body movements distribution of the subjects}

The mean (mean \pm S.D)* of other body movements distribution of the subjects was $1.91 \pm .292$ and the median was 2. Test of proportion has shown that most of the subjects, i.e. $145(90.6 \%)$ were significantly higher in number with no other body movements than the subjects with other body movements such as legtapping etc. i.e. 15 (9.4\%).

\section{Anxious mood distribution of the subjects}

The mean $(\operatorname{mean} \pm \text { S.D })^{*}$ of anxious mood distribution of the subjects was $1.32 \pm 1.326$ and the median was 1 . Test of proportion has shown that most of the subjects, i.e. 58(36.3\%) were significantly higher in mild anxious mood distribution of the subjects than the other subjects as follows: Not present (31.3\%), Moderate (12.5\%), Severe (7.5\%), Very severe $(12.5 \%)$.

$*$ = Based on the coding given to the stuttering parameters while using SPSS statistical version 20.

\subsection{ANOVA}

\section{Anxious mood distribution of subjects}

A one- way analysis of variance was used between the subjects to compare the impact of anxious mood on the clinical category of subjects (Stuttering with anxiety, Stuttering alone and Control). The value of $\mathrm{F}$ $(2,157)=181.256$ with $\mathrm{P} \leq 0.001$ indicates the test of significance following the impact of anxious mood on the clinical category of subjects.

All the values are expressed as mean \pm S.D. and the different categories of subjects were analyzed by oneway ANOVA followed by Tukey's Post Hoc test.

Table 1 displays statistical values of Tukey's Post Hoc test for anxious mood distribution of subjects. The comparison between stuttering with anxiety subjects and stuttering alone subjects were found to be significant (mean \pm SD $(.75 \pm .588), \mathrm{P} \leq 0.001)$ of the stuttering alone group as compared to control group (mean $\pm \mathrm{SD}(0.68 \pm .725), \mathrm{P} \leq 0.001)$ of the control group. The comparison between stuttering alone subjects and stuttering with anxiety subjects were found to be significant (mean $\pm \mathrm{SD}(3.25 \pm .870), \mathrm{P} \leq 0.001)$ of stuttering with anxiety group, but has no statistically significant difference with the control group (mean \pm SD (.68 \pm .725$), P=0.858)$. The comparison between the control subjects and stuttering with anxiety subjects were found to be significant (mean \pm SD $(3.25 \pm .870), \mathrm{P}$ $\leq 0.001$ ) of stuttering with anxiety group, but has no statistically significant difference with the stuttering alone group (mean $\pm \mathrm{SD}(.75 \pm .588), \mathrm{p}=0.858)$.

The rating of anxious mood is coded as:

0 - Not present, 1 - Mild, 2 - Moderate, 3 - Severe, 4 Very severe

From the graph given in figure 1, it is concluded that the anxious mood showed more impact on the subjects under the categorization of stuttering with anxiety as compared to the stuttering alone subjects. However, it is also observed from the graph that the control subjects also had a little impact of anxious mood but was lesser than the subjects under the categorization of stuttering alone.

\section{Repetition of words distribution of subjects}

A one- way analysis of variance was used between the subjects to compare the effect of the clinical category of subjects (Stuttering with anxiety, stuttering 
alone and Control) on repetition of words. The value of $\mathrm{F}(2,157)=64.473$ with $\mathrm{P} \leq 0.001$ indicates the test of significance following the impact of the clinical category of subjects on repetition of words.

All the values are expressed as mean \pm S.D. and the different categories of subjects were analyzed by oneway ANOVA followed by Tukey's Post Hoc test.

Table 2 displays statistical values of Tukey's Post Hoc test for repetition of words distribution of subjects. The comparison between stuttering with anxiety subjects and control subjects were found to be significant ( mean \pm SD $(5.00 \pm .000), \mathrm{P} \leq 0.001)$ of the control group, but has no statistically significant difference with the stuttering alone group (mean \pm SD (2.80 \pm 1.937$), \quad \mathrm{P}=0.932$ ). The comparison between stuttering alone subjects and control subjects were found to be significant (mean \pm SD $(5.00 \pm .000), \mathrm{P} \leq 0.001$ of the control group, but has no statistically significant difference with stuttering with anxiety group (mean \pm SD (2.70 \pm 1.604$), \quad P=0.932)$. The comparison between control subjects and stuttering with anxiety subjects were found to be significant (mean \pm SD $(2.70 \pm 1.604)$, $\mathrm{p} \leq 0.001$ of stuttering with anxiety group as compared to stuttering alone group (mean \pm SD $(2.80 \pm 1.937)$, $\mathrm{p} \leq 0.001$ )

The rating of repetition of words is coded as:

6-7 times - 1, 4-5 times - 2, 2-3 times - 3, Sometimes 4 , None -5

From the graph given in figure 2, it is concluded that subjects under the categorization of stuttering with anxiety had more impact on the repetition of words i.e. stuttering with anxiety subjects tends to repeat more words due to the effect of anxiety on them as compared to the stuttering alone subjects. Whereas, stuttering alone subjects also tend to repeat the words but lesser than the subjects under the categorization of stuttering with anxiety subjects.

\section{Prolongation of words distribution of subjects}

A one- way analysis of variance was used between the subjects to compare the effect of the clinical category of subjects (Stuttering with anxiety, stuttering alone and Control) on the prolongation of words. The value of $\mathrm{F}(2,157)=102.838$ with $\mathrm{P} \leq 0.001$ indicates the test of significance following the impact of the clinical category of subjects on the prolongation of words.

All the values are expressed as mean \pm S.D. and the different categories of subjects were analyzed by oneway ANOVA followed by Tukey's Post Hoc test.

Table 3 displays statistical values of Tukey's Post Hoc test for prolongation of words distribution of subjects. The comparison between stuttering with anxiety subjects and stuttering alone subjects were found to be significant (mean \pm SD $\quad(2.13 \pm 1.588)$, $\mathrm{p} \leq 0.018$ of the stuttering alone group as compared to the control group (mean $\pm \mathrm{S}(5.00 \pm 0.00), \mathrm{p} \leq 0.001)$. The comparison between stuttering alone subjects and stuttering with anxiety subjects were found to be significant $\quad($ mean \pm SD $\quad(2.83 \pm 1.683), \quad \mathrm{p} \leq 0.018) \quad$ of stuttering with anxiety group as compared to the control group (mean \pm SD $\quad(5.00 \pm 0.00), \quad p \leq 0.001)$. The comparison between control subjects and stuttering with anxiety subjects were found to be significant (mean \pm SD $(2.83 \pm 1.631), \quad \mathrm{p} \leq 0.001$ of stuttering with anxiety group as compared to the stuttering alone group $($ mean \pm SD $(2.13 \pm 1.588), \mathrm{p} \leq 0.001)$.

The rating of prolongation of words is coded as:

2-3 seconds -1 , 4-5 seconds $-2,6-7$ seconds -3 , More than seven seconds -4 , None -5

From the graph given in the figure 3 , it is concluded that the subjects under the categorization of stuttering with anxiety had more impact on the prolongation of words i.e. stuttering with anxiety subjects tends to take more time to take out the words due to the effect of anxiety on them as compared to the stuttering alone subjects. Whereas, stuttering alone subjects also take the time to get the words out but lesser than the subjects under the categorization of stuttering alone.

\section{Blockage of words distribution of subjects}

A one- way analysis of variance was used between the subjects to compare the effect of the clinical category of subjects (Stuttering with anxiety, stuttering alone and Control) on blockage of words. The value of $\mathrm{F}(2,157)=104.096$ with $\mathrm{P} \leq 0.001$ indicates the test of significance following the impact of the clinical category of subjects on blockage of words.

All the values are expressed as mean \pm S.D. and the different categories of subjects were analyzed by oneway ANOVA followed by Tukey's Post Hoc test.

Table 4 displays statistical values of Tukey's Post Hoc test for blockage of words distribution of subjects. The comparison between stuttering with anxiety subjects and stuttering alone subjects were found to be significant (mean \pm SD $(1.20 \pm 0.405)$, $\mathrm{p} \leq 0.03$ ) of the stuttering alone group as compared to the control group $(\operatorname{mean} \pm \mathrm{SD}(2.00 \pm 0.00), \mathrm{p} \leq 0.001)$. The comparison between stuttering alone subjects and stuttering with anxiety subjects were found to be significant $\quad($ mean \pm SD $\quad(1.38 \pm 0.490), \quad \mathrm{p} \leq 0.039) \quad$ of stuttering with anxiety group as compared to the control group (mean \pm SD $\quad(2.00 \pm 0.00), \quad \mathrm{p} \leq 0.001)$. The comparison between control subjects and stuttering with anxiety subjects were found to be significant (mean \pm SD $(1.38 \pm 0.490), \quad \mathrm{p} \leq 0.001$ of stuttering with anxiety group as compared to the stuttering alone group (mean \pm SD (1.20 \pm 0.405$), \mathrm{p} \leq 0.001)$.

The rating of blockage of words is coded as:

Yes -1 , No -2

From the graph given in figure 4 , it is concluded that the subjects under the categorization of stuttering alone tend to stuck more on words as compared to the subjects under the categorization of stuttering with 
anxiety. So, in this graph, it is right to say that anxiety may not or have a little impact on blockage of words.

\section{Facial movements distribution of subjects}

A one- way analysis of variance was used between the subjects to compare the effect of the clinical category of subjects (Stuttering with anxiety, stuttering alone and Control) on facial movements. The value of $\mathrm{F}$ $(2,157)=111.655$ with $\mathrm{P} \leq 0.001$ indicates the test of significance following the impact of the clinical category of subjects on facial movements.

All the values are expressed as mean \pm S.D. and the different categories of subjects were analyzed by oneway ANOVA followed by Tukey's Post Hoc test.

Table 5 displays statistical values of Tukey's Post Hoc test for facial movements distribution of subjects. The comparison between stuttering with anxiety subjects and control subjects were found to be significant (mean $\pm \mathrm{SD}(2.00 \pm 0.000), \mathrm{P} \leq 0.001)$ of the control group, but has no statistically significant difference with the stuttering alone group (mean \pm SD (1.30 \pm 0.464$), \quad \mathrm{P}=0.533)$. The comparison between stuttering alone subjects and control subjects were found to be significant (mean \pm SD $\quad(2.00 \pm 0.000)$, $\mathrm{P} \leq 0.001$ of the control group, but has no statistically significant difference with stuttering with anxiety group (mean \pm SD (1.23 \pm 0.423$), P=0.533)$. The comparison between control subjects and stuttering with anxiety subjects were found to be significant (mean \pm SD (1.23 \pm 0.423$), p \leq 0.001$ of stuttering with anxiety group as compared to the stuttering alone group (mean $\pm \mathrm{SD}$ $(1.30 \pm 0.464), \mathrm{p} \leq 0.001)$.

The rating of facial movements is coded as:

Yes -1 , No -2

From the graph given in figure 5, it is concluded that the subjects under the categorization of stuttering with anxiety had more impact on facial movements i.e. the subjects under the categorization of stuttering with anxiety tends to make more facial movements as compared to the subjects under the categorization of stuttering alone.

\section{Hand movements distribution of subjects}

A one- way analysis of variance was used between the subjects to compare the effect of the clinical category of subjects (Stuttering with anxiety, stuttering alone and Control) on hand movements. The value of $\mathrm{F}$ $(2,157)=16.177$ with $\mathrm{P} \leq 0.001$ indicates the test of significance following the impact of the clinical category of subjects on hand movements.

All the values are expressed as mean \pm S.D. and the different categories of subjects were analyzed by oneway ANOVA followed by Tukey's Post Hoc test.

Table 6 displays statistical values of Tukey's Post Hoc test for hand movements distribution of subjects. The comparison between stuttering with anxiety subjects and control subjects were found to be significant (mean $\pm \mathrm{SD}(1.86 \pm 0.347), \mathrm{P} \leq 0.001)$ of the control group, but has no statistically significant difference with the stuttering alone group (mean \pm SD (1.45 \pm 0.504$), \quad \mathrm{P}=0.863)$. The comparison between stuttering alone subjects and control subjects were found to be significant (mean \pm SD $(1.86 \pm 0.347)$, $\mathrm{P} \leq 0.001$ ) of the control group, but has no statistically significant difference with stuttering with anxiety group (mean \pm SD (1.50 \pm 0.506$), \mathrm{P}=0.863)$. The comparison between control subjects and stuttering with anxiety subjects were found to be significant (mean \pm SD $(1.50 \pm 0.506), p \leq 0.001)$ of stuttering with anxiety group as compared to the stuttering alone group (mean $\pm \mathrm{SD}$ $(1.45 \pm 0.504), p \leq 0.001)$.

The rating of hand movement is coded as:

Yes -1 , No -2

From the graph given in figure 6 , it is concluded that the subjects under the categorization of stuttering alone had more impact on hand movements i.e. the subjects under the categorization of stuttering alone tends to make more hand movements as compared to the subjects under the categorization of stuttering with anxiety. So, in this graph, it is right to say that anxiety may not or have a little impact of hands movements of PWS.

\section{Other body movements distribution of subjects}

A one- way analysis of variance was used between the subjects to compare the effect of the clinical category of subjects (Stuttering with anxiety, stuttering alone and Control) on other body movements. The value of $F(2,157)=9.873$ with $\mathrm{P} \leq 0.001$ indicates the test of significance following the impact of the clinical category of subjects on other body movements.

All the values are expressed as mean \pm S.D. and the different categories of subjects were analyzed by oneway ANOVA followed by Tukey's Post Hoc test.

Table 7 displays statistical values of Tukey's Post Hoc test for other body movements distribution of subjects. The comparison between stuttering with anxiety subjects and control subjects were found to be significant (mean $\pm \mathrm{SD}(2.00 \pm 0.000), \mathrm{P} \leq 0.016)$ of the control group, but has no statistically significant difference with the stuttering alone group (mean \pm SD (1.85 \pm 0.362$), \quad \mathrm{P}=0.449)$. The comparison between stuttering alone subjects and control subjects were found to be significant (mean \pm SD $(2.00 \pm 0.000)$, $\mathrm{P} \leq 0.016$ ) of the control group, but has no statistically significant difference with stuttering with anxiety group (mean $\pm \mathrm{SD}$ (1.78 \pm 0.423$), \mathrm{P}=0.449)$. The comparison between control subjects and stuttering with anxiety subjects were found to be significant (mean \pm SD $(1.78 \pm 0.423), p \leq 0.001)$ of stuttering with anxiety group as compared to the stuttering alone group (mean $\pm \mathrm{SD}$ (1.85 \pm 0.362$), p \leq 0.016)$.

The rating of other body movements is coded as: Yes -1 , No -2

From the graph given in figure 7 , it is concluded that the subjects under the categorization of stuttering 
with anxiety had more impact on other body movements i.e. the subjects under the categorization of stuttering with anxiety tends to make more other body movements such as leg tapping, body tremors etc. as compared to the subjects under the categorization of stuttering alone subjects.

Table 1: Comparison between the three groups on the basis of anxious mood

\begin{tabular}{|l|l|c|c|}
\hline $\begin{array}{c}\text { (I) Clinical } \\
\text { category of subjects }\end{array}$ & \multicolumn{1}{|c|}{$\begin{array}{c}\text { (J) Clinical category of } \\
\text { subjects }\end{array}$} & $\begin{array}{c}\text { Mean } \\
\text { Differenc } \\
\text { e (I-J) }\end{array}$ & Significant \\
\hline \multirow{2}{*}{$\begin{array}{l}\text { Stammering with } \\
\text { anxiety }\end{array}$} & Stammering alone & $2.500^{*}$ & 0.001 \\
\cline { 2 - 4 } & Control & $2.575^{*}$ & 0.001 \\
\hline \multirow{2}{*}{ Stammering alone } & Stammering with anxiety & $-2.500^{*}$ & 0.001 \\
\cline { 2 - 4 } & Control & .075 & 0.858 \\
\hline & Stammering with anxiety & $-2.575^{*}$ & 0.001 \\
\cline { 2 - 4 } & Stammering alone & -.075 & 0.858 \\
\hline
\end{tabular}

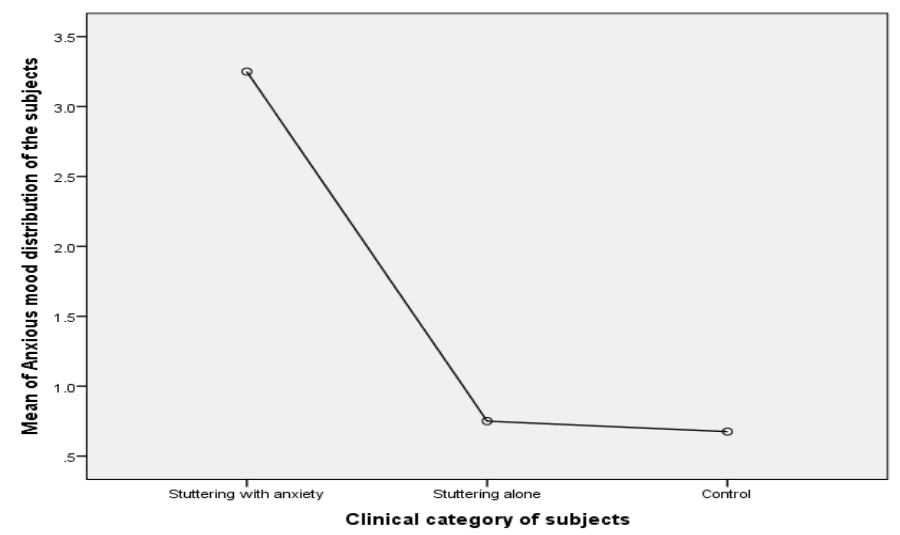

Fig. 1: Impact of anxious mood on clinical category

Table 2: Comparison between the three groups on the basis of repetition of words

\begin{tabular}{|c|c|c|c|}
\hline $\begin{array}{l}\text { (I) Clinical } \\
\text { category of } \\
\text { subjects }\end{array}$ & $\begin{array}{c}\text { (J) Clinical category of } \\
\text { subjects }\end{array}$ & $\begin{array}{c}\text { Mean } \\
\text { Difference } \\
\text { (I-J) }\end{array}$ & Significant \\
\hline \multirow{2}{*}{$\begin{array}{l}\text { Stammering with } \\
\text { anxiety }\end{array}$} & Stammering alone & -.100 & 0.932 \\
\hline & Control & $-2.300^{*}$ & 0.001 \\
\hline \multirow[t]{2}{*}{ Stammering alone } & $\begin{array}{l}\text { Stammering with } \\
\text { anxiety }\end{array}$ & .100 & 0.932 \\
\hline & Control & $-2.200^{*}$ & 0.001 \\
\hline \multirow[t]{2}{*}{ Control } & $\begin{array}{l}\text { Stammering with } \\
\text { anxiety }\end{array}$ & $2.300^{*}$ & 0.001 \\
\hline & Stammering alone & $2.200^{*}$ & 0.001 \\
\hline
\end{tabular}

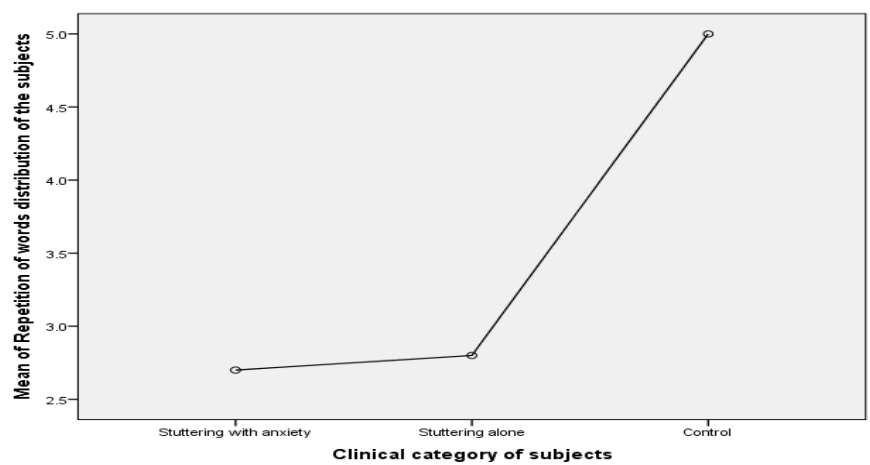

Fig. 2: Impact of clinical categories on repetition of words 
Table 3: Comparison between the three groups on the basis of prolongation of words

\begin{tabular}{|c|c|c|c|}
\hline $\begin{array}{c}\text { (I) Clinical } \\
\text { category of } \\
\text { subjects }\end{array}$ & $\begin{array}{c}\text { (J) Clinical category of } \\
\text { subjects }\end{array}$ & $\begin{array}{c}\text { Mean } \\
\text { Difference } \\
(\mathbf{I}-\mathbf{J})\end{array}$ & Significant \\
\hline \multirow{2}{*}{$\begin{array}{c}\text { Stammering with } \\
\text { anxiety }\end{array}$} & Stammering alone & $.700^{*}$ & 0.018 \\
\cline { 2 - 4 } & Control & $-2.175^{*}$ & 0.001 \\
\hline \multirow{2}{*}{ Stammering alone } & Stammering with anxiety & $-.700^{*}$ & 0.018 \\
\cline { 2 - 4 } & Control & $-2.875^{*}$ & 0.001 \\
\hline \multirow{2}{*}{ Control } & Stammering with anxiety & $2.175^{*}$ & 0.001 \\
\cline { 2 - 4 } & Stammering alone & $2.875^{*}$ & 0.001 \\
\hline
\end{tabular}

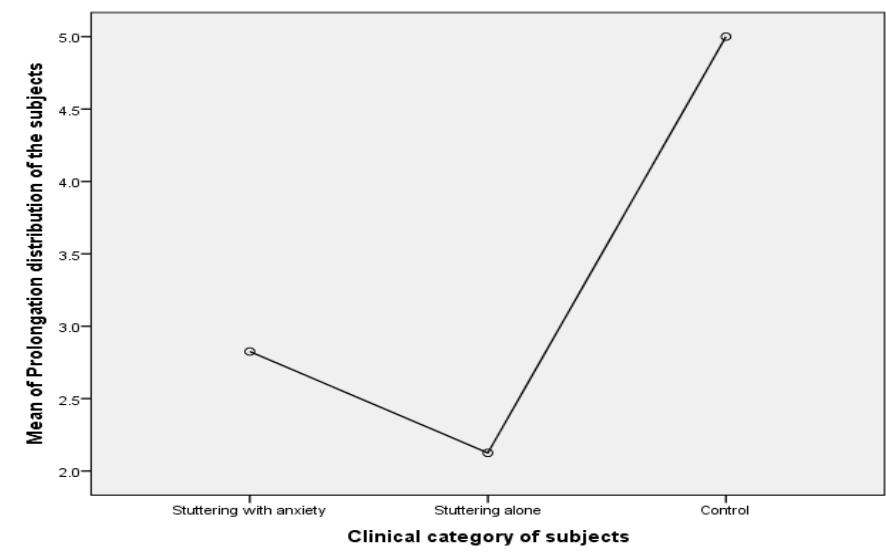

Fig. 3: Impact of clinical categories on prolongation of words

Table 4: Comparison between the three groups on the basis of blockage of words

\begin{tabular}{|l|l|l|l|}
\hline $\begin{array}{c}\text { (I) Clinical } \\
\text { category of } \\
\text { subjects }\end{array}$ & $\begin{array}{c}\text { (J) Clinical category of } \\
\text { subjects }\end{array}$ & $\begin{array}{c}\text { Mean } \\
\text { Difference } \\
(\mathbf{I}-\mathbf{J})\end{array}$ & Significant \\
\hline \multirow{2}{*}{$\begin{array}{l}\text { Stammering with } \\
\text { anxiety }\end{array}$} & Stammering alone & $.175^{*}$ & 0.039 \\
\cline { 2 - 4 } & Control & $-.625^{*}$ & 0.001 \\
\hline \multirow{2}{*}{ Stammering alone } & Stammering with anxiety & $-.175^{*}$ & 0.039 \\
\cline { 2 - 4 } & Control & $-.800^{*}$ & 0.001 \\
\hline \multirow{2}{*}{ Control } & Stammering with anxiety & $.625^{*}$ & 0.001 \\
\cline { 2 - 4 } & Stammering alone & $.800^{*}$ & 0.001 \\
\hline
\end{tabular}

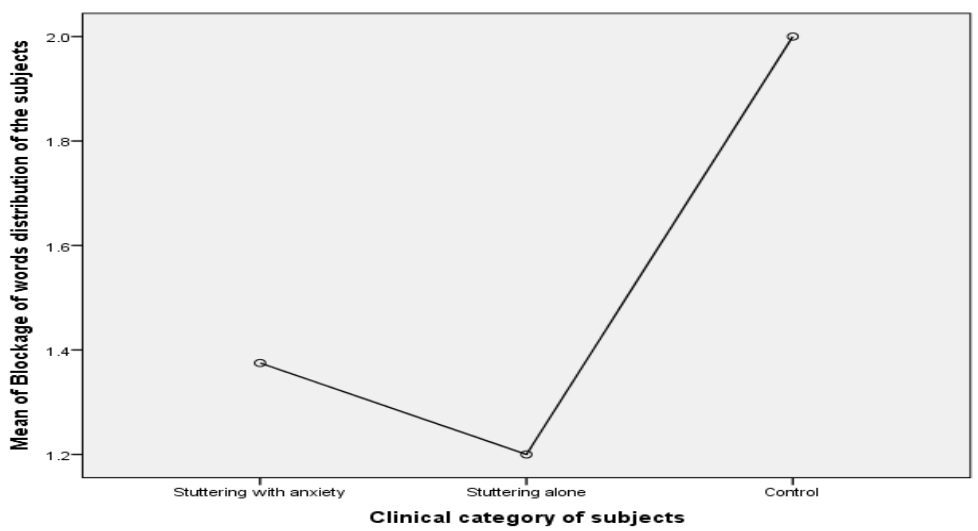

Fig. 4: Impact of clinical category on blockage of words 
Table 5: Comparison between the three groups on the basis of facial movements

\begin{tabular}{|l|l|c|c|}
\hline $\begin{array}{c}\text { (I) Clinical } \\
\text { category of } \\
\text { subjects }\end{array}$ & $\begin{array}{c}\text { (J) Clinical category of } \\
\text { subjects }\end{array}$ & $\begin{array}{c}\text { Mean } \\
\text { Difference } \\
\text { (I-J) }\end{array}$ & Significant \\
\hline \multirow{2}{*}{$\begin{array}{l}\text { Stammering with } \\
\text { anxiety }\end{array}$} & Stammering alone & -.075 & 0.533 \\
\cline { 2 - 4 } & Control & $-.775^{*}$ & 0.001 \\
\hline \multirow{2}{*}{ Stammering alone } & Stammering with anxiety & .075 & 0.533 \\
\cline { 2 - 4 } & Control & $-.700^{*}$ & 0.001 \\
\hline \multirow{2}{*}{ Control } & Stammering with anxiety & $.775^{*}$ & 0.001 \\
\cline { 2 - 4 } & Stammering alone & $.700^{*}$ & 0.001 \\
\hline
\end{tabular}

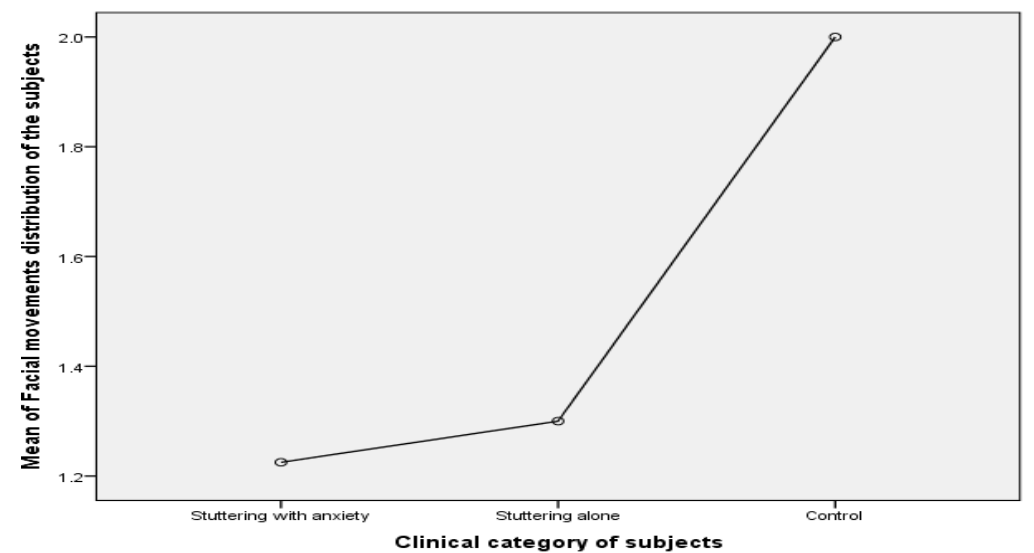

Fig. 5: Impact of clinical category on facial movements

Table 6: Comparison between the three groups on the basis of hand movements

\begin{tabular}{|l|l|c|c|}
\hline $\begin{array}{c}\text { (I) Clinical category } \\
\text { of subjects }\end{array}$ & $\begin{array}{c}\text { (J) Clinical } \\
\text { category of subjects }\end{array}$ & $\begin{array}{c}\text { Mean } \\
\text { Difference } \\
\text { (I-J) }\end{array}$ & Significant \\
\hline $\begin{array}{l}\text { Stammering with } \\
\text { anxiety }\end{array}$ & Stammering alone & .050 & 0.863 \\
\cline { 2 - 4 } & Control & $-.363^{*}$ & 0.001 \\
\hline \multirow{2}{*}{ Stammering alone } & $\begin{array}{l}\text { Stammering with } \\
\text { anxiety }\end{array}$ & -.050 & 0.863 \\
\cline { 2 - 4 } & Control & $-.413^{*}$ & 0.001 \\
\hline Control & $\begin{array}{l}\text { Stammering with } \\
\text { anxiety }\end{array}$ & $.363^{*}$ & 0.001 \\
\cline { 2 - 4 } & Stammering alone & $.413^{*}$ & 0.001 \\
\hline
\end{tabular}

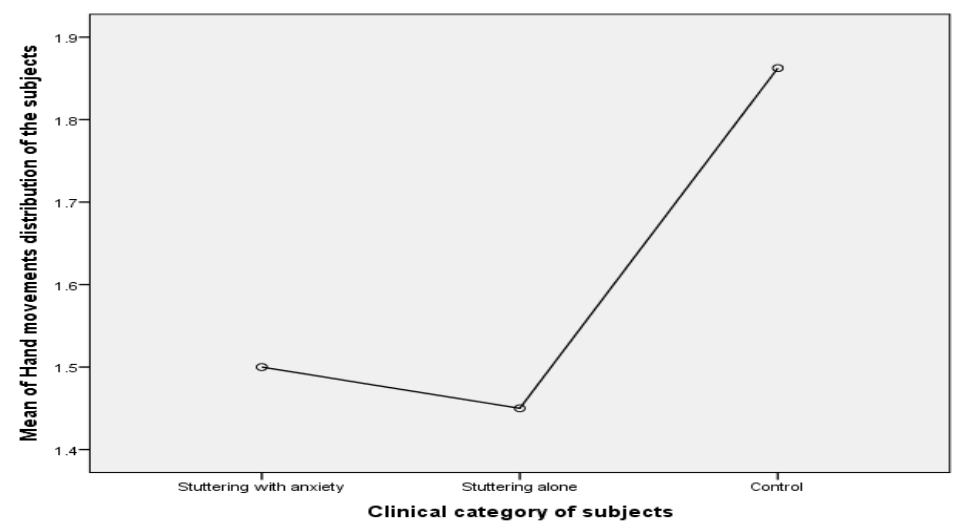

Fig. 6: Impact of clinical category on hand movements 
Table 7: Comparison between the three groups on the basis of other body movements

\begin{tabular}{|l|l|c|c|}
\hline \multirow{2}{*}{$\begin{array}{c}\text { (I) Clinical } \\
\text { category of subjects }\end{array}$} & \multicolumn{1}{|c|}{$\begin{array}{c}\text { (J) Clinical category of } \\
\text { subjects }\end{array}$} & $\begin{array}{c}\text { Mean } \\
\text { Difference } \\
(\mathbf{I}-\mathbf{J})\end{array}$ & Sig. \\
\hline \multirow{2}{*}{$\begin{array}{l}\text { Stammering with } \\
\text { anxiety }\end{array}$} & Stammering alone & .075 & 0.449 \\
\cline { 2 - 4 } & Control & $-.225^{*}$ & 0.001 \\
\hline \multirow{2}{*}{ Stammering alone } & Stammering with anxiety & -.075 & 0.449 \\
\cline { 2 - 4 } & Control & $-.154^{*}$ & 0.016 \\
\hline \multirow{2}{*}{ Control } & Stammering with anxiety & $.225^{*}$ & 0.001 \\
\cline { 2 - 4 } & Stammering alone & $.150^{*}$ & 0.016 \\
\hline
\end{tabular}

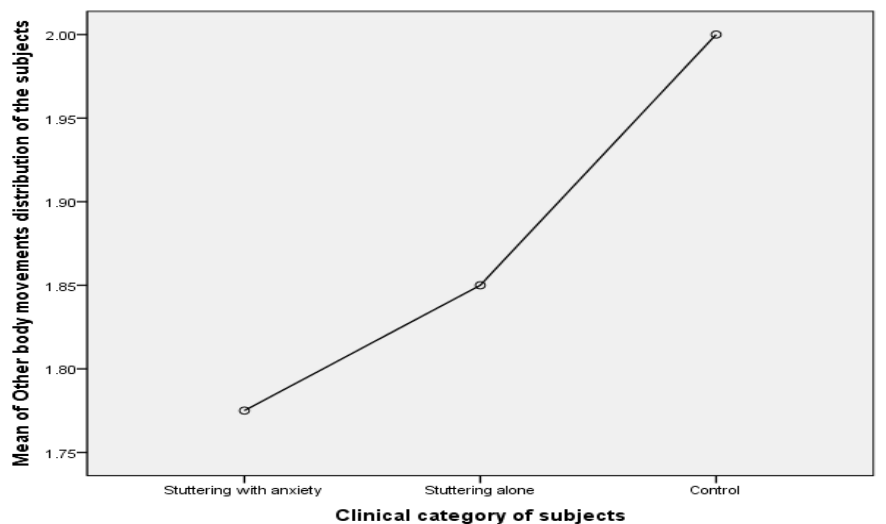

Fig. 7: Impact of clinical category on other body movements

\section{Discussion}

Stuttering is a fluency disorder commonly associated with broken speech in which the normal flow of communication is interrupted by repetition (I want I want I want this), prolongation (hhhhhey mmmy naaaaame is) or abnormal stoppage (blocks) of words and sounds. Anxiety is a mental illness associated with overwhelming worry. An individual suffering from anxiety is self-conscious about his surroundings and over-reacts to social situations. Various previous reports and in clinical studies, it has been noted that stuttering shows a correlation with anxiety. Following this, the present study has shown an increase in the levels of anxiety in PWS in social situations which support the outcomes of the study reported by. ${ }^{23}$ Further, my data is supported by personal interview taken at the time of data collection. Subjects also reported that during social situations i.e. at the time of the interview, talking before a group and while talking to a stranger or higher authorities, their speech becomes worse because of the rise in an anxious mood. Thus, our study is aimed to investigate that whether PWS have a significant relationship with anxiety or not when compared to PWDS.

Few clinical studies demonstrated the use of dopamine blockers (haloperidol or risperidone) and reported that with the administration of such compounds there was a decrease in the magnitude of stuttering and so as the neurobehavioural alterations which affect the rate of facial expression made by the stuttering subjects. These pieces of evidence clearly state that excessive dopaminergic activity in stuttering subjects have a strong impact on PWS. So, it can be assumed that the higher levels of anxiety in PWS with raised dopamine concentration in Broca's area influence the timing of speech. In our study, during the time of the interview, it was observed that the subjects with altered neurobehavioural aspects were more liable to stutter. So, it can be summarized that with the rise in anxiety, PWS may always have neurobehavioural abnormalities which affect the rate of stuttering.

Prevalence of higher levels of anxiety among the PWS group was reported in two ways i.e. Firstly, based on the total scores obtained from the Hamilton Anxiety Rating Scale (HAM-A) and Secondly, the mean scores of anxious mood in PWS group. Results of the present study revealed a significant difference between PWS and PWDS on measures of anxiety. This was confirmed by the total scores obtained from (HAM-A) as well as the mean score of anxious mood obtained statistically. Moreover, in the present study, there was a sub-group of PWS (stuttering alone group) who reported very little or no rise in the levels of anxiety when compared to the fluent subjects and this may lead to a little or no impact of anxiety on them.

Previous research has further demonstrated that the adult PWS have Generalized Anxiety which is found in addition to experiencing anxiety specific to speaking situations. Conversely, Blood and co-investigators concluded specifically that PWS did not demonstrate 
any more generalized anxiety than PWDS. In addition, Miller and Watson reported that PWS did not differ significantly from PWDS on any measures of anxiety, but only with regard to communication apprehension. ${ }^{24}$

Present study justified the impact of anxiety on PWS regarding the type of stuttering they deal with (repetition of words, prolongation of words, and blockage of words) and so as the severity. The level of anxiety and its correlation with stuttering was reflected by repetition, prolongation, and blockage of words. However, it should be noted that the anxiety had a very little or no impact on the blockage of words parameter of stuttering since the mean score of blockage of words revealed that the subjects under the categorization of stuttering alone group tend to stuck more on words as compared to the subjects under the categorization of stuttering with anxiety. The mean score of different parameters of stuttering except for blockage of words also highlighted that the severity of stuttering depends on the levels of anxiety. The severity of stuttering (repetition and prolongation of words) increases in PWS with an increase in the levels of anxiety i.e. PWS tends to stutter more on words with an elevated anxious mood.

Previous research has also pointed a valuable relationship between stuttering severity and anxiety levels. ${ }^{25}$ These studies indicated that as the severity of stuttering increased so did the level of anxiety. A more negative attitude towards communication has also been tied to higher levels of stuttering severity. ${ }^{26,27}$ Stuttering severity is associated with emotions such as embarrassment, frustration, and apprehension of negative social evaluation. As such, greater anxiety levels should be associated with a higher frequency of stuttering. However, there is a conflicting statement in the literature regarding the relationship between Generalized Anxiety and stuttering severity in PWS. However, Ezrati-Vinacour and Levin found no differences in generalized anxiety levels of individual PWS as a function of stuttering severity. Blood and coworkers also found no associations between stuttering severity and generalized anxiety as measured by cortisol levels and the STAI in adult PWS. ${ }^{28}$ In addition, Craig and Hancock found no relationship between stuttering severity and trait or state anxiety in CWS aged 9 to 14 year. $^{29}$

Various types of neurotransmitters are present in the CNS and are believed to be involved in various physiological functions. Alternations in these neurotransmitters can result in mental illness like anxiety, depression, etc. most abundant of the neurotransmitters like dopamine, GABA and glutamate are well implicated to be involved in coordinating the motor activity as well as play a crucial role in anxiety. Degeneration of nigrostriatal dopaminergic neuron and the paucity of dopamine is unable to regulate the normal GABA and glutamate activity in the limbic area. Over gabaminergic activity impinges the normal motor influxes, affects the facial expression as well as reduces the speech fluency of an individual. Earlier, it was well reported that the anxious patients show more stuttering comparable with the others which indicate the role of anxiety and its associated neurobehavioural changes with stuttering. Studies have reported the effect of anxiety on communication and found that the anxious subjects had higher pitched voice, increased muscular tension, laryngopharyngeal resonance, and dysfluency.

In the present study, the relationship between anxiety and neurobehavioural changes were provided as the mean scores of neurobehavioural parameters of stuttering i.e. facial movements, hands movements, and other body movements obtained statistically and direct observation of neurobehavioural changes shown by the subjects at the time of interview taken/data collection. The results of the present study revealed that there is a significant relationship between anxiety and the neurobehavioural changes in PWS. The results of the present study were confirmed by the mean scores of neurobehavioural parameters of stuttering i.e. facial movements, hands movements and other body movements obtained statistically. It was confirmed that with the rise in anxiety PWS showed more neurobehavioural changes as compared to the control subjects. However, it should be noted that the anxiety had a very little or no effect on hands movement parameter of stuttering since the mean score of hands movement revealed that the subjects under the categorization of stuttering alone tend to make more hand movements as compared to the subjects under the categorization of stuttering with anxiety. So, it is right to say that anxiety may not or have a little impact on hand movements in PWS. Since there is a significant relationship between anxiety and the neurobehavioural changes, further, there is a need to conduct a study on a large population with the same assumption because there are few kinds of literature associated with the relationship of anxiety and neurobehavioural changes in PWS.

\section{Conclusion}

In the present study, PWS showed a significant relationship of anxiety with stuttering. There was a significant impact of anxiety on stuttering. PWS showed a significant rise in the level of anxiety on the basis of anxious mood when compared to fluent people (control group) and the various parameters of stuttering such as prolongation of words, repetition of words, and blockage of words were affected by the rise in the level of anxiety. A wide variability of scores on the Hamilton scale of Anxiety and the data collection form for stuttering suggests that the levels of anxiety are very individualized and there was a sub-group of PWS who had little or no impact of anxiety on their stutter and hence the subjects were divided into two groups i.e. stuttering with anxiety subjects and stuttering alone 
subjects. However, PWS tend to experience higher levels, likely due to years of managing negative social encounters. The present study also showed significant neurobehavioural changes such as facial movements, tremor, and leg tapping etc. in PWS due to the effect of anxiety on them. These research findings add to the literature that there is an impact of anxiety on stuttering and neurobehavioural changes in PWS. The provision of effective early treatment for stuttering may be beneficial in preventing the potential development of anxiety and negative communication attitudes in PWS.

Conflict of Interest: All the authors do not have any conflict in this article.

\section{Appendix A}

Hamilton Anxiety Rating Scale (HAM-A) Hamilton $M$. The assessment of anxiety states by rating.

1. Administration time: $10-15$ minutes

2. Population: Children, adolescents, and adults

3. Purpose: To assess the severity of anxiety symptoms

A.1. Instructions for administration

Below is a list of phrases that describe the certain feeling that people have. Rate the patients by finding the answer which best describes the extent to which he/she has these conditions. Select one of the five responses for each of the fourteen questions. The rating of symptoms is coded as:
a. $0=$ Not present
b. $1=$ Mild
c. $2=$ Moderate
d. $3=$ Severe
e. $4=$ Very severe

A.2. Symptoms based questions

1. Anxious mood 01234 : Worries, anticipation of the worst, fearful anticipation, irritability.

2. Tension 0123 4: Feelings of tension, fatigability, startle response, moved to tears easily, trembling, feelings of restlessness, inability to relax.

3. Fear 0123 4: Of dark, of strangers, of being left alone, of animals, of traffic, of crowds.

4. Insomnia0 123 4: Difficulty in falling asleep, broken sleep, unsatisfying sleep, and fatigue on waking, dreams, nightmares, night terrors.

5. Intellectual 0123 4: Difficulty in concentration, poor memory

6. Depressed mood 0123 4: Loss of interest, lack of pleasure in hobbies, depression, early waking, diurnal swing.

7. Somatic (muscular) 0123 4: Pains and aches, twitching, stiffness, myoclonic jerks, grinding of teeth, unsteady voice, increased muscular tone.

8. Somatic (sensory) 0123 4: Tinnitus, blurring of vision, hot and cold flushes, feelings of weakness, pricking sensation.
9. Cardiovascular symptoms 01223 4: Tachycardia, palpitations, pain in chest, throbbing of vessels, fainting feelings, missing beat.

10. Respiratory symptoms $\begin{array}{llllll}0 & 1 & 2 & 3 & 4 \text { : Pressure or }\end{array}$ constriction in chest, choking feelings, sighing, dyspnea.

11. Gastrointestinal symptoms 0123 4: Difficulty in swallowing, wind abdominal pain, burning sensations, abdominal fullness, nausea, vomiting, borborygmi, looseness of bowels, loss of weight, constipation.

12. Genitourinary symptoms 0123 4: Frequency of micturition, urgency of micturition, amenorrhea, menorrhagia, development of frigidity, premature ejaculation, loss of libido, impotence.

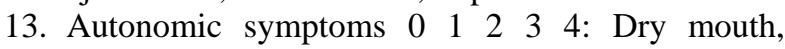
flushing, pallor, tendency to sweat, giddiness, tension headache, raising of hair.

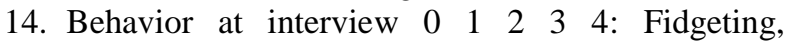
restlessness or pacing, tremor of hands, furrowed brow, strained face, sighing or rapid respiration, facial pallor, swallowing, etc.

\section{References}

1. Costa D, Kroll R. Stuttering: An update for physicians. Canadian Medical Association Journal,2000;162,1849-56.

2. Felsenfeld S, Kirk K. M. Zhu G. Statham D. J. Neale M. C \& Martin N. G. A study of the genetic and environmental etiology of stuttering in a selected twin sample. Behavior Genetics,2000;30,359-66.

3. Guitar B. Stuttering: An integrated approach to its nature and treatment. (3rd ed.). Baltimore, MD: Williams and Wilkins, 2006.

4. Gillam R B, Marquardt T. P. Martin F. N. Fluency Disorders. In R.B. Gillam, T.P. Marquardt, \& F.N. Martin (Eds.), Communication sciences anddisorders: From science to clinical practice. San Diego, $C A$ : Singular Publishing Group, Thomson Learning, 2000;313-39.

5. Bloodstein O. A handbook on stuttering(5th ed.). San Diego, CA: Singular, 1995.

6. Craig A, Hancock K. Tran Y. Craig M. Anxiety levels in people who stutter: A randomized population study. Journal of Speech, Language, andHearing Research,2003;46,1197206.

7. Miller S, Watson BC. The relationship between communication attitude, anxiety, and depression in stutterers and nonstutterers. Journal of Speech and Hearing Research,1992;(35),789-799.

8. Barrera T L, Norton P J. Quality of life impairment in generalized anxiety disorder, social phobia, and panic disorder. Journal of Anxiety Disorders, 23,2009;(8),10861090.

9. American Psychiatric Association (APA). Diagnostic and statistical manual of mental disorders(4th ed.). Washington, DC: APA, 1994.

10. Blood GW, Blood IM. Bennet S. Simpson K C. Susman E J. Subjective anxiety measurements and Cortisol responses in adults who stutter. Journal of Speech and Hearing Research, 1994;37,760-768.

11. Menzies R G, Onslow M. Packman A. Anxiety and stuttering:Exploring a complex relationship. American Journal of Speech-Language Pathology, 1999;8,3-10.

12. Stein M B, Baird A. Walker J R. Social phobia in adults with stuttering. American Journal of Psychiatry, 
1996;153,278-80.

13. Kraaimaat F W, Vanryckeghem M, Van Dam-Baggen R. Stuttering and social anxiety. Journal of Fluency Disorders, 2002; 27, 319-31.

14. Blumgart E, Tran Y. Craig A. Social anxiety disorder in adults who stutter. Depression and Anxiety, 2010;27 (7), 687-92.

15. Iverach L, O’Brian S. Jones M. Block S. Lincoln M. Harrison E. et al. Prevalence of anxiety disorders among adults seeking speech therapy for stuttering. Journal of Anxiety Disorders, 2009;23(7),928-34.

16. Caruso A J. Chodzko-Zajko W J. Bidinger D A. Sommers R K. Adults who stutter: Responses to cognitive stress. Journal of Speech andHearing Research,1994;37,746-54.

17. Ezrati-Vinacour R, Levin I. The relationship between anxiety and stuttering: A multidimensional approach. Journal of Fluency Disorders,2004;29,135-48.

18. Van Dam-Baggen R, Kraaimaat FW. Sociaalvaardigheidstherapie: Een cognitiefgedragstherapeutische groepsbehandeling. [Social skills training: A cognitive-behavioral grouptherapy]. Houten: Bohn, Stafleu \& Van Loghum, 2000.

19. Van Dam-Baggen R, Kraaimaat F W. Group social skills training or cognitive group therapy as a clinical treatment of choice for generalized social phobia? Journal of Anxiety Disorders, 2000;14,437-51.

20. Van Dam-Baggen R, Kraaimaat F W. Social skills training in two subtypes of psychiatric inpatients with generalized social phobia. Scandinavian Journal of Behaviour Therapy, 2000;29,14-21.

21. Wittchen U. The many faces of social anxiety disorder. International Clinical Pharmacology, 15(Supplement), 2000;S7-S12.

22. Hamilton M. The assessment of anxiety states by rating. British Journal of Psychology, 1959; 32, 50-55.

23. Craig A. An investigation into the relationship between anxiety and stuttering. Journal of Speech and Hearing Disorders, 1990; 55,290-4.

24. Andrews G, Harris M. The syndrome of stuttering. Clinics in Developmental Medicine,1964; 1-17.

25. Fitzgerald H E, Djurdjic S D, Maguin E. Assessment of sensitivity to interpersonal stress in stutterers. Journal of Communication Disorders, 1992; 25,31-42.

26. Gunn A, Menzies R G. O’Brian S. Onslow M. Packman A. Lowe R. et al. Axis I anxiety and mental health disorders among stuttering adolescents. Journal of Fluency Disorders, 2013;9, 1-11.

27. Mulcahy K, Hennessey N. Beilby J. Byrnes M. Social anxiety and the severity and typography of stuttering in adolescents. Journal of Fluency Disorders, 2008; 33 (4),306-19.

28. Spielberger C D, Gorsuch R L. Luschene T L. Manual for the State-Trait Anxiety Inventory (Self-Evaluation Questionnaire). Palo Alto, California: Consulting Psychologists Press, 1970.

29. Craig A, Hancock K. Anxiety in children and young adolescents who stutter. American Journal of Human Communication Disorders, 1996;24(1),28-38. 